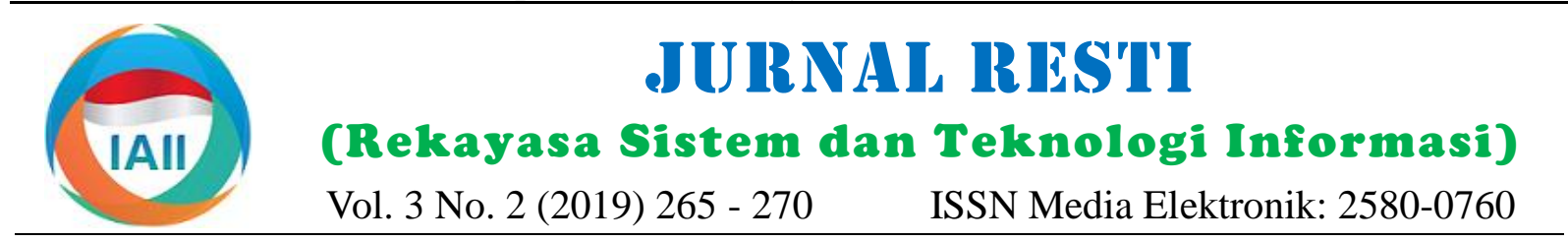

\title{
Alat Monitoring Detak Jantung Untuk Pasien Beresiko Berbasis IoT Memanfaatkan Aplikasi OpenSID berbasis Web
}

\author{
Yuhefizar $^{1}$, Anggara Nasution ${ }^{2}$, Roni Putra ${ }^{3}$, Ervan Asri ${ }^{4}$, Deni Satria ${ }^{5}$ \\ $1,3,4,5$ Jurusan Teknologi Informasi, Politeknik Negeri Padang \\ ${ }^{2}$ Jurusan Teknik Elektro, Politeknik Negeri Padang \\ yuhefizar@pnp.ac.id
}

\begin{abstract}
Patients with arrhythmia symptoms must undergo a healthy lifestyle and routinely conduct consultations and heart rate control with the doctor. The most important thing about this is the integrated health monitoring tool. In this study a portable heart rate monitoring tool is proposed for patients at risk of low-cost IoT-based with SMS alert system utilizing the OpenSID database. . Module ESP8266 Wi-Fi is used to communicate the web server gateway and pulse sensor to detect the heart rate which converted to Bit per Minute (BPM). Heart rate data is saved to the database server using TCP IP communications. Patients and doctors can see heart rate information trough the website in real-time. Alert system will send notification information via short message service (SMS ) to doctors, person in charge and family if heart rate below 60 BPM and above 100 BPM. the time needed for sending SMS is about 7 to 8 seconds. Test results show the whole system is running well. This tool is expected can accompany the risk patients do their activities safely and both doctors and families easier to supervise the patients.
\end{abstract}

Keywords: IoT, Heartbeat, Monitoring, ESP8266 WiFi, Pulse sensor, OpenSID, Web, System alerts, SMS.

\begin{abstract}
Abstrak
Pasien dengan gejala aritmia harus menjalani pola hidup yang sehat dan rutin melakukan konsultasi serta pegontrolan detak jantung dengan dokter. Hal yang paling utama dari hal tersebut yaitu alat monitoring kesehatan yang terintegrasi. Dalam penelitian ini diusulkan alat portable monitoring detak jantung untuk pasien yang beresiko berbasis IoT berbiaya rendah dengan sms alert system memanfaatkan database OpenSID. Menggunakan modul Wifi ESP8266 untuk komunikasi ke gateway web server dan pulse sensor untuk mendeteksi detak jantung yang dikonversi ke Bit per Minute (BPM). Data detak jantung kemudian disimpan ke database server menggunakan komunikasi TCP/IP. informasi detak jantung secara realtime dengan tampilan website. Alert sistem akan mengirim sms kepada dokter/tenaga kesehatan dan keluarga jika nilai detak jantung dibawah 60 BPM dan diatas 100 BPM, waktu yang dibutuhkan untuk pengiriman sms berdurasi sekitar 7 sampai 8 detik. Hasil pengujian menunjukkan seluruh sistem berjalan dengan baik. Dengan alat ini pasien beresiko dapat beraktifitas lebih aman dan dokter serta keluarga lebih mudah untuk mengawasi pasien.
\end{abstract}

Kata kunci: IoT, Detak jantung, Monitoring, WiFi ESP8266, Pulse sensor, OpenSID, Web, Alert system, sms.

(C) 2019 Jurnal RESTI

\section{Pendahuluan}

Perkembangan teknologi informasi sekarang ini ditandai oleh hadirnya Internet Of Thing (IoT). IoT merupakan layanan internet yang terintegrasi dengan pemanfaatan jenis sensor tertentu [1][2][3][4][5][6][7][8], hal ini juga berdampak pada perawatan kesehatan. Permasalahan perawatan pasien yang dulu dilakukan secara tradisional, dimana para dokter atau ahli kesehatan harus berada di dekat pasien setiap waktu dan pasien tetap dilingkungan rumah sakit, saat ini permasalahan tersebut dapat diatasi dengan pendekatan berorientasi pasien. Dalam pendekatan ini pasien dilengkapi dengan pengetahuan dan informasi untuk lebih aktif dalam mendiagnosa penyakit dan melakukan tindakan pencegahan. salah satunya pengukuran detak jantung. Denyut jantung merupakan bagian yang sangat vital bagi tubuh manusia. Dengan mengetahui detak jantung dapat mengetahui informasi mengenai tingkat kebugaran, tingkat stress dan aktivitas jantung (kondisi Diterima Redaksi : 07-07-2019 | Selesai Revisi : 03-08-2019| Diterbitkan Online : 08-08-2019 
kardiovaskular), salah satu penyakit yang dapat dideteksi dari denyut jantung adalah penyakit jantung.

Data Kementerian Kesehatan RI pada 2013 juga menyebut penyakit ini masih termasuk dalam 10 penyakit tidak menular dengan prevalensi tertinggi. penyakit jantung atau kardiovaskuler adalah penyakit yang disebabkan gangguan pada jantung dan pembuluh darah, termasuk diantaranya adalah gangguan irama jantung (aritmia). Di Indonesia penyakit jantung mencapai 26,4 persen [9]. Aritmia adalah kelainan jantung yang ditandai dengan detak atau ritme yang tidak normal, bisa terlalu cepat, terlalu pelan, atau tidak teratur. Aritmia terjadi apabila impuls elektrik tidak berfungsi. Gejalanya antara lain detak jantung lambat atau cepat, debaran di dada, nyeri dada, sesak napas, pusing, jika tidak dilakukan tindakan medis dengan cepat bisa menyebabkan kematian. Pasien dengan gejala aritmia harus menjalani pola hidup yang sehat dan rutin melakukan konsultasi serta pegontrolan detak jantung dengan dokter / ahli kesehatan [10].

Hal yang paling utama dari hal tersebut yaitu alat monitoring kesehatan yang terintegrasi. alat monitoring ini harus dapat memperoleh, merekam dan menampilkan data dari tubuh pasien setiap saat serta mempunyai sistem alarm dimana untuk memperingatkan pasien dan penyedia layanan perawatan kesehatan jika data yang dipantau melewati batas normal. Oleh karena itu alat ini juga harus terintegrasi dengan sistem database dalam satu server. Penelitian pemanfaatan IoT untuk monitoring detak jantung telah banyak dilakukan. Dalam penelitiannya David L dkk mengukur detak jantung pasien menggunakan sensor infrared dan photodioda, data detak jantung pasien kemudian dikirim ke smartphone menggunakan komunikasi bluetooth, jika detak jantung pasien tidak normal smartphone pasien akan menelepon ke dokter atau keluarga pasien yang telah ditentukan. Jarak komunikasi bluetooth yang terbatas yang hanya 10 meter menjadi suatu kendala selain itu panggilan telepon darurat juga terbatas [11].

Menggunakan Bluetooth heart rate modul untuk mendeteksi denyut jantung Muhammad Farouq dkk menggembangkan aplikasi seluler untuk pasien berpenyakit jantung. Aplikasi berbasis android ini memiliki fiture mendeteksi denyut jantung dan notifikasi SMS serta posisi pasien jika denyut jantng tidak normal. Jarak komunikasi Bluetooth yang terbatas juga menjadi kendala pada penelitian ini [12].

G.Vijay dkk juga mengembangkan sebuah alat monitoring detak jantung dan tekanan darah serta suhu tubuh. Data kemudian tersimpan ke database dan ditampilkan di website. Data pasien dapat dilihat oleh dokter setiap saat. Komunikasi data menggunakan bluetooth dengan jarak yang masih terbatas, tidak ada notifikasi seperti panic button, SMS maupun E-mail jika pasien dalam keadaan darurat [13].
Pada paper ini dibangun sistem monitoring detak jantung untuk pasien yang beresiko dengan konsep IoT menggunakan modul wifi esp8266 berbiaya rendah, sistem dapat berkomunikasi antara sensor jantung dan gateway server web. Detak jantung pasien dapat dimonitoring dan disimpan setiap waktu untuk dianalisis. Sistem ini dapat mengirimkan alarm sms kepada dokter/tenaga kesehatan serta keluarga jika detak jantung pasien kurang atau melewati batas normal. Alat monitoring pada penelitian ini diintegrasikan pada aplikasi OpenSID, website yang di dedikasikan untuk desa-desa di seluruh pelosok tanah air, untuk bisa menggambarkan situasi, potensi yang ada di desa tersebut serta desa dapat mengirimkan informasi (warta desa) kepada masyarakat-masyarakat yang ada di desa bahkan untuk masyarakat luas. Tujuan dari penelitian ini adalah untuk merancang dan membuat suatu alat sistem monitoring dan notifikasi detak jantung dan suhu tubuh seseorang menggunakan sistem IoT yang di monitoring pada aplikasi OpenSID.

\section{Metode Penelitian}

Metode yang digunakan dalam penelitian ini adalah pembuatan prototype alat yang dimulai dari perancangan system yang akan disusun dan direalisasikan dalam sebuah objek atau alat yang akan dirancang. Dalam proses perancangan alat ini terbagi dalam tiga tahapan yaitu :

1. Membuat blok diagram sistem.

2. Perancangan perangkat keras (hardware).

3. Perancangan perangkat lunak (software).

\subsection{Blok Diagram Sistem}

Gambar 1 menunjukan arsitektur system wireless monitoring detak jantung berbasis internet of thing dengan system peringatan menggunakan sms. Sistem terdiri pulse sensor berbasis esp8266 wifi dengan menggunakan protocol TCP/IP untuk komunikasi. Sistem yang kami usulkan mengintegrasikan pulse PPG sensor, gateway IOT dan system berbasis aplikasi mobile web OpenSID.id sistem monitoring pada personal computer (PC) menggunakan web interface untuk smartphone menggunakan android application dengan menampilkan grafik dan nilai detak jantung pasien.

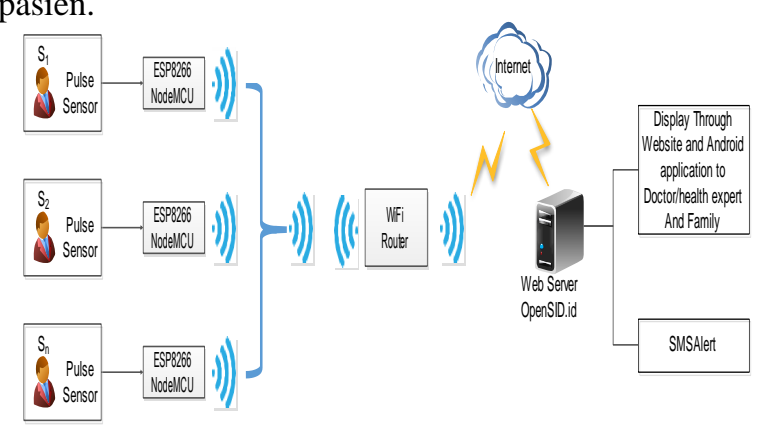

Gambar 1. Blok Diagram Sistem 


\subsection{Perancangan Perangkat Keras (Hardware)}

Rangkaian elektronik dari alat dapat dilihat pada gambar 2. Alat ini menggunakan pulse sensor untuk mendeteksi detak jantung pasien. Pulse sensor bekerja dengan cara memanfaatkan cahaya. Saat sensor ini diletakkan dipermukaan kulit, sebagian besar cahaya yang diserap atau dipantulkan oleh organ dan jaringan (kulit, tulang, otot, darah), namun beberapa cahaya akan melewati jaringan tubuh jika mereka cukup tipis. Jika jumlah intensitas cahaya yang mengenai pulse sensor tetap makan nilai sinyal akan berada di sekitar 512 (nilai tengah rentang ADC 10 bit). Makin besar intensitas cahaya makin tinggi nilai ADC. Sinyal yang dihasilkan oleh sensor menghasilkan gelombang yang dinamakan photoplethysmogram(PPG) ditunjukkan pada Gambar 3. PPG dalam dunia medis digunakan untuk pengukuran respiratory rate (pernafasan) dan heart rate (denyut jantung) [14]

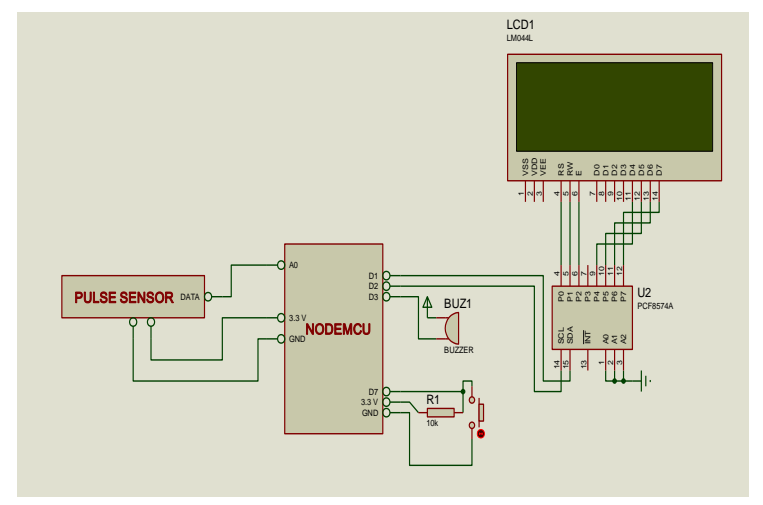

Gambar 2. Rangkaian Elektronika Alat monitoring Jantung

Pulse sensor mempunyai 3 buah pin yang difungsikan berbeda. Pin 1 digunakan sebagai pin data yang terhubung ke pin A0 pada mikrokontroler Saat jantung memompa darah ke seluruh tubuh, setiap denyut yang terjadi disertai dengan munculnya gelombang pulsa seperti gelombang kejut yang merambat melalui arteri hingga ke lapisan kapiler tangan (jemari) tempat pulse sensor dipasang. Kecepatan darah mengalir lebih lambat daripada gelombang pulsa. Penentuan jumlah denyut jantung per menit (BPM = beat per minute) dengan sensor ini dilakukan dengan membagi 60000 (dalam milidetik) nilai rata-rata dari sepuluh IBI (inter beat interval) yang telah dilalui. IBI adalah selisih waktu antara satu titik dengan titik berikutnya dengan nilai titik tersebut adalah $50 \%$ dari nilai $\mathrm{P}$ (puncak) dikurangi $\mathrm{T}$ (lembah) pada saat grafik terjadi kenaikan tajam
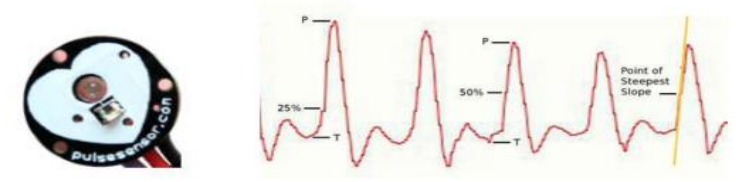

Gambar 3. Pulse sensor
I2C LCD digunakan menampilkan nilai detak jantung pada LCD, modul ini dikendalikan secara serial sinkron dengan protocol I2C/IIC (inter integrated circuit) atau TWI (Two Wire interface) dengan alamat 0x27 dan 0x37. Resistor 10K berfungsi sebagai externall pull-up resistor. Dengan adanya pull-up resistor, mikrokontroler akan membaca logika '1' saat tidak ada penekanan saklar. Tanpa adanya pull-up resistor, pin I/O akan mengambang dan mikrokontroler dapat membacanya sebagai logika ' 1 ' ataupun '0'. Pada gambar diatas rangkaian saklar push-button terhubung dengan GPIO14 yang berfungsi sebagai panic button untuk mengaktifkan Buzzer yang terhubung pada pin GPIO12.

\subsection{Perancangan Perangkat Lunak (Software)}

Dalam perancangan dan pembuatan perangkat lunak (software) pada penelitian ini, komunikasi sensor dengan mikrokontroler dan seluruh proses menggunakan bahasa $\mathrm{C}$ software arduino IDE. Sedangkan pada bagian komunikasi mikrokontroler dengan server menggunakan bahasa pemograman PHP untuk kemudian dikirim dan disimpan pada database OpenSID yang menggunakan aplikasi PHP MyAdmin, aplikasi ini ditampilkan melalui web browser menggunakan software PHP, Ajax dan Java script.

Flowchart sistem pulse sensor dengan modul ESP8266 wifi dapat dilihat pada gambar 4. Proses dimulai dari inisialiasi UART, SSID dan password, pulse sensor dan LCD. Detak jantung akan tampil pada LCD jika telah terkoneksi pada jaringan. Selanjutnya data detak jantung pasien dikirim ke database server untuk disimpan menggunakan protocol TCP/IP. Kemudian sistem akan melakukan pengecekkan, jika panic button $(\mathrm{PB})=$ ' 1 ' maka buzzer akan berbunyi dan informasi dikirim ke database server. Setelah data detak jantung tersimpan di database. Data tersebut kemudian diolah dan ditampilkan pada aplikasi android dan website.

Pasien dan dokter dapat melihat detak jantung setiap saat. Detak jantung manusia normal berkisar antara 60100 BPM, jika detak jantung dibawah atau melewati ketentuan tersebut diperkiraan pasien memiliki kelainan detak jantung. Alert sistem yang diusulkan mempunyai konsep sama, setelah data masuk ke tabel database, data tersebut akan dibandingkan jika kecil dari 60 BPM dan besar dari 100 BPM maka alert sistem akan aktif, sms akan terkirim ke dokter. Begitu juga jika pasien menekan panic button, maka alert sistem akan aktif dan sms juga terkirim ke penanggung jawab pasien seperti yang terlihat pada gambar 5 .

\section{Hasil dan Pembahasan}

Pada bagian ini akan diperlihatkan hasil pengujian dari sistem yang telah dibuat. Pengujian dilaksanakan dua tahap. Pertama pengujian Pulse sensor dengan ESP8266 Wi-Fi module Kedua pengujian alert sistem. 


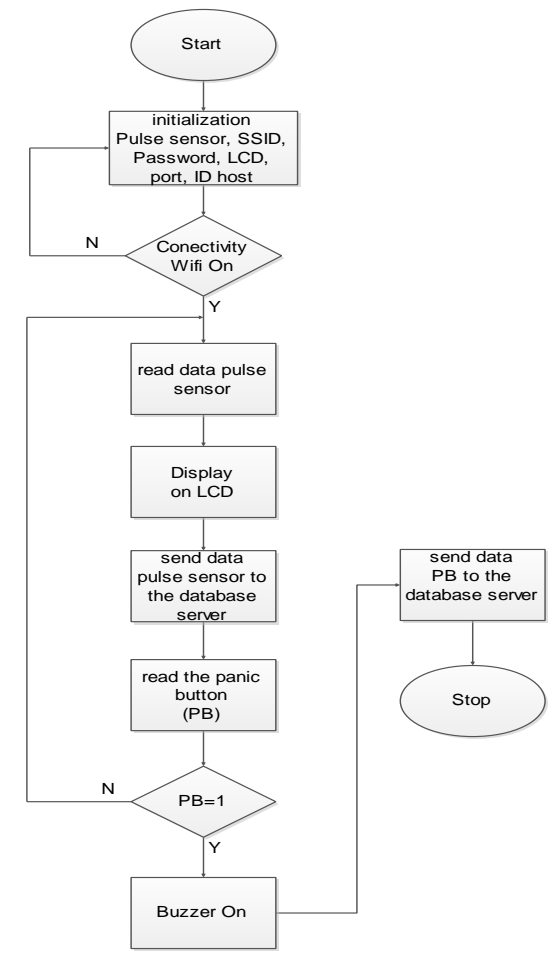

Gambar 4. Flowchart Alat Monitoring

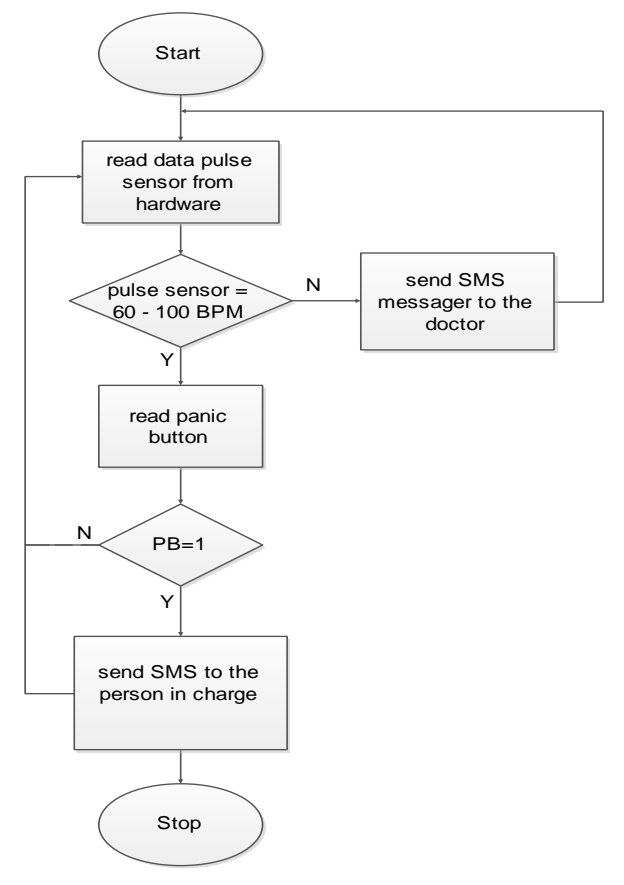

Gambar 5. Flowchart SMS Alert

\subsection{Pengujian Pulse sensor dengan ESP8266 Wi-Fi}

Pengujian ini dilakukan untuk melihat apakah pulse sensor dapat menampilkan data detak jantung pasien pada LCD dan menyimpannya di database server dan kemudian menampilkannya pada website untuk pasien dan dokter. Gambar 6 menunjukkan prototype alat yang dibuat, pulse sensor dipasang pada ujung jari pasien, nilai detak jantung ditampilkan pada LCD kemudian dibandingkan dengan alat Pulse Oximeter. Lihat Gambar 6. Pulse Oximeter adalah alat yang digunakan untuk mengukur detak jantung (HR=heart rate) dan biasanya digunakan untuk bayi premature atau pasien dalam kondisi khusus. Cara menguji dan mengukur detak jantung yaitu dengan meletakkan pulse sensor pada ujung jari telunjuk. Hasil pengujian dapat dilihat pada tabel 1.

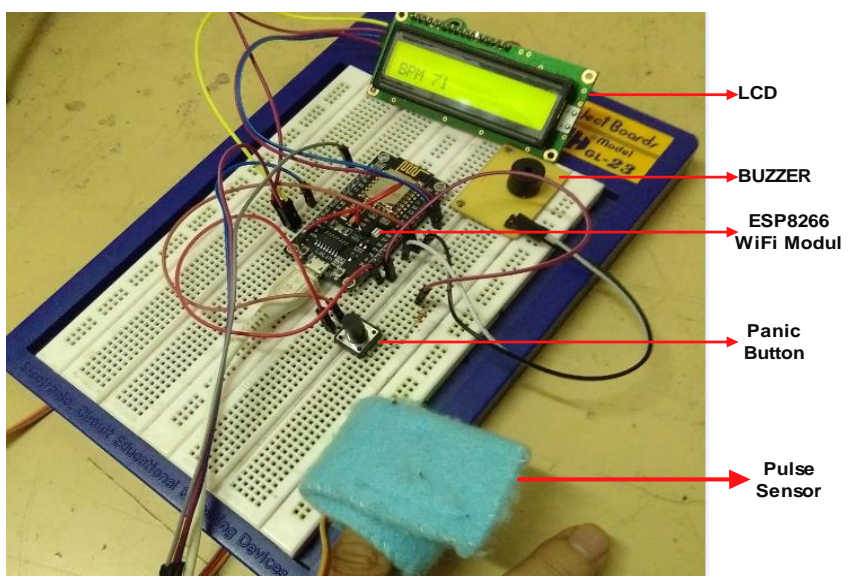

Gambar 6. Pengujian Pulse sensor dengan ESP8266 Wi-Fi module

Tabel 1. Hasil Pengukuran dan Pengujian Pulse sensor

\begin{tabular}{ccccc}
\hline $\begin{array}{c}\text { Testing } \\
\text { (person } \\
\text { number) }\end{array}$ & $\begin{array}{c}\text { Umur } \\
\text { (Tahun) }\end{array}$ & $\begin{array}{c}\text { Pengukuran } \\
\text { menggunakan } \\
\text { Pulse } \\
\text { Oximeter } \\
(\text { BPM) }\end{array}$ & $\begin{array}{c}\text { Pengukuran } \\
\text { menggunakan } \\
\text { Pulse } \\
\text { Sensor on } \\
\text { LCD (BPM) }\end{array}$ & $\begin{array}{c}\text { Error } \\
(\%)\end{array}$ \\
\hline 1 & 18 & 76 & 79 & 3.94 \\
2 & 21 & 65 & 70 & 7.69 \\
3 & 24 & 69 & 72 & 4.34 \\
4 & 25 & 70 & 73 & 4.28 \\
5 & 30 & 76 & 80 & 5.26 \\
6 & 33 & 72 & 75 & 4.16 \\
7 & 35 & 79 & 83 & 5.06 \\
8 & 42 & 80 & 83 & 3.75 \\
9 & 46 & 77 & 82 & 5.19 \\
10 & 54 & 79 & 3.79 \\
& Error rata-rata Pengukuran & & 4.750 \\
\hline \multicolumn{5}{r}{}
\end{tabular}

Rata-rata kesalahan dapat dilihat pada tabel 1, ini menunjukkan hasil pengujian dan pengukuran rangkaian denyut jantung. Pulse sensor dapat mengukur serta mendeteksi denyut jantung, yang ditampilkan di LCD dengan rata-rata kesalahan $4.750 \%$. Data detak jantung kemudian disimpan ke database server menggunakan komunikasi TCP/IP, koneksi ke jaringan WiFi dibuat jeda waktu selama $500 \mathrm{~ms}$. Setelah proses koneksi client selesai maka diberikan delay selama 1000ms yang dimaksudkan agar sensor bersiap-siap dan selanjutnya akan dimulai pembacaan data dari pulse sensor. Modul ESP8266 bekerja secara multitasking agar dapat menampilkan data pada LCD dan database server secara bersamaan dengan menggunakan fungsi millis(). Setelah data sensor diperoleh data tersebut dikirim ke database openSID Untuk menyimpan data kesehatan penduduk maka 
dibuatlah tabel baru bernama tweb_penduduk data yang terkirim sesuai dengan data cek kesehatan di _kesehatan. Agar data bisa tersambung ke data klinik.. Pengaktifan sms alert sistem pada sistem ini penduduk, kita harus merelasikan tabel-tabel tersebut jika nilai detak jantung dibawah 60 BPM dan diatas sehingga data jatung, nama penduduk, tempat lahir, 100 BPM dihitung sebanyak sepuluh kali maka sistem tanggal lahir serta alamat bisa ditampilkan, seperti yang akan mengirim sms. Hasil pengujian waktu untuk terlihat pada gambar 7 dan 8 .

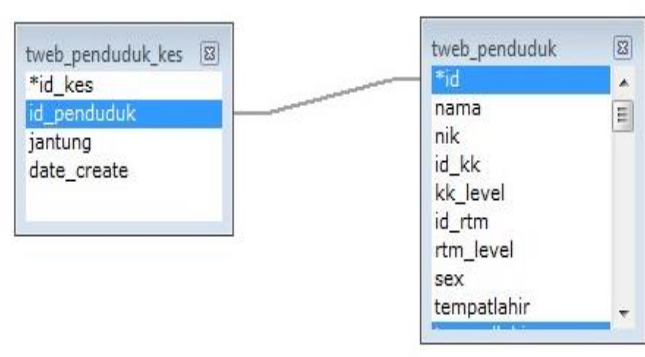

Gambar 7. Relasi tabel pada database OpenSID

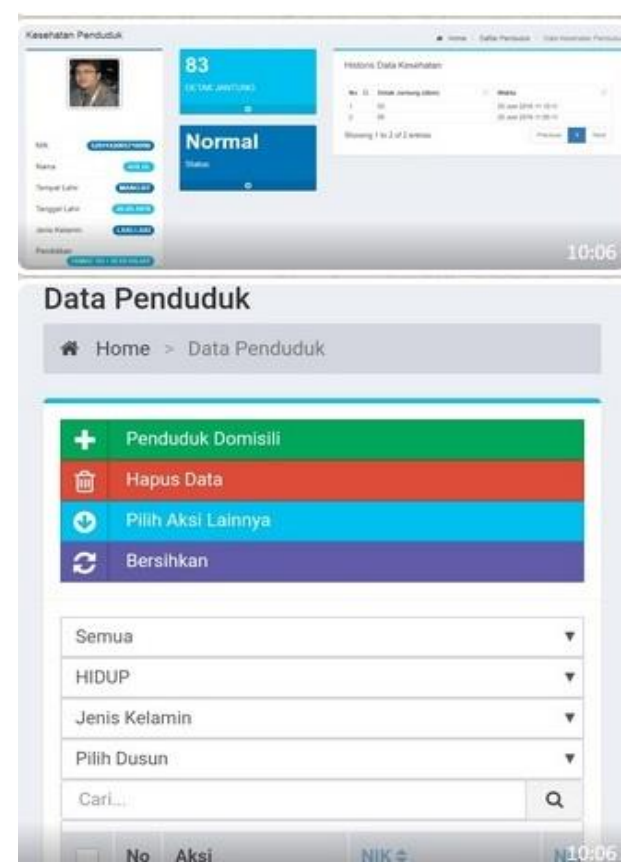

Gambar 8. Tampilan Monitoring detak jantung pada Aplikasi OpenSID

\subsection{Pengujian SMS Alert Sistem}

Pada penelitian ini untuk sms gateway kami menggunakan Gammu. Gammu adalah sebuah aplikasi cross platform yang digunakan untuk menjembatani / mengkomunikasikan antara database SMS Gateway dengan sms devices. Aplikasi Gammu berupa daemon yang berjalan secara background. Setiap saat, gammu memonitor sms devices dan database sms gateway. Untuk bisa mengirim sms melalui gammu, kita harus menambahkan tabel gammu di database openSID yang terdiri dari (inbox,outbox,sentitems), agar bisa data berupa sms dikirim oleh gammu ke penduduk, kita harus membuat relasi terlebih dahulu, ada tiga tabel yang terkait (tweb_penduduk, tweb_penduduk_kes, sentitems) relasi antara tabel tersebut berfungsi agar mengirim notifikasi sms dapat dilihat pada tabel 6 . Relasi antar tabel dan tampilan sms gateway dapat dilihat pada gambar 9 .

Tabel 2. Pengujian jangka waktu untuk mengirim notifikasi SMS

\begin{tabular}{ccc}
\hline Percobaan & Notifikasi SMS & waktu \\
\hline 1 & Ada & 8 detik \\
\hline 2 & Ada & 9 detik \\
\hline 3 & Ada & 8 detik \\
\hline 4 & Ada & 8 detik \\
\hline 5 & Ada & 7 detik \\
\hline 6 & Ada & 9 detik \\
\hline 7 & Ada & 10 detik \\
\hline 8 & Ada & 8 detik \\
\hline 9 & Ada & 9 detik \\
\hline 10 & Ada & 8 detik \\
\hline
\end{tabular}

Berdasarkan percobaan dari tabel 2, waktu yang dibutuhkan untuk pengiriman sms berdurasi sekitar 7 sampai 8 detik
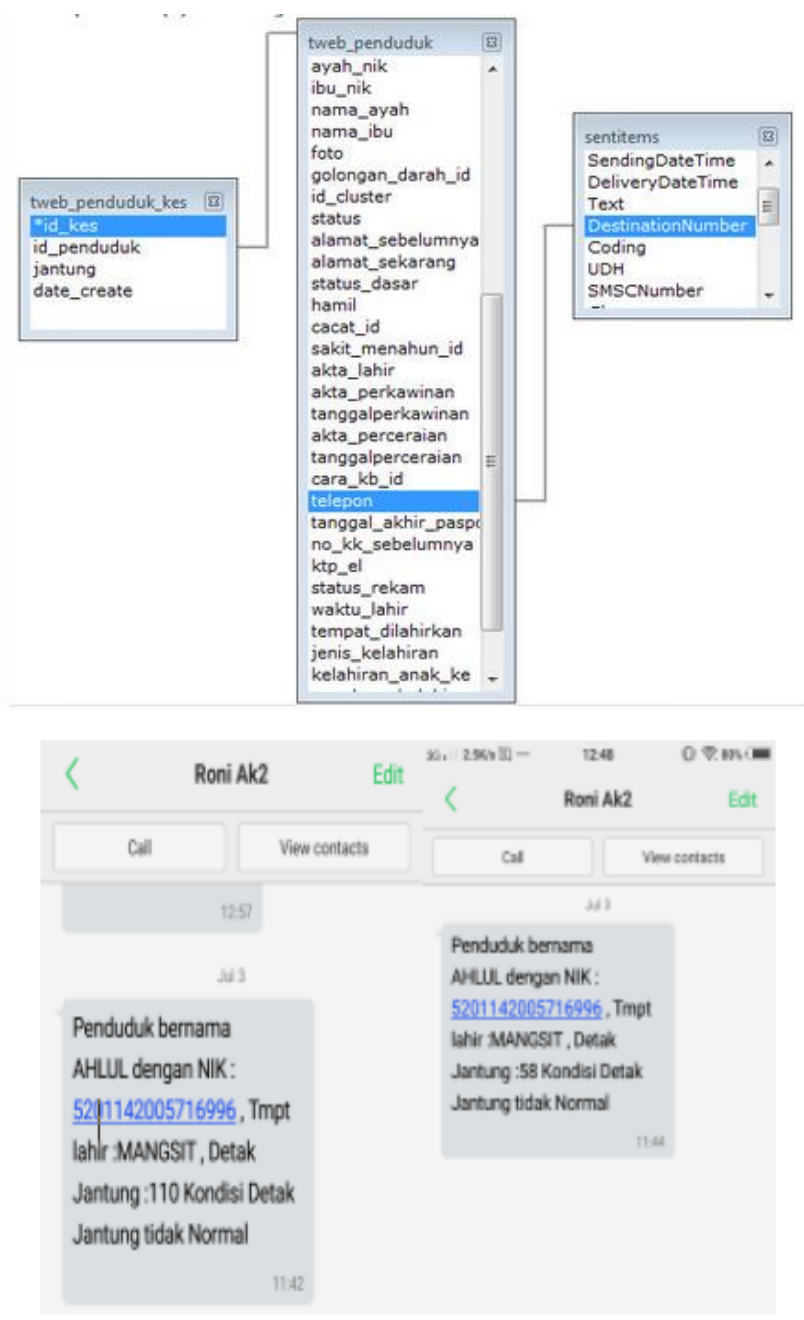

Gambar 9. Tampilan relasi database dan SMS gateway 


\section{Kesimpulan}

Pada penelitian ini, kami mengusulkan IoT untuk [6] sistem monitoring detak jantung dengan komunikasi WiFi berbiaya rendah menggunakan modul wifi ESP8266 memanfaatkan OpenSID sebagai database. Nilai detak jantung dapat ditampilkan pada LCD dan [7] website secara realtime. Pasien dan dokter dapat melihat informasi detak jantung setiap saat pada website. Sms alert sistem akan aktif jika nilai detak jantung dibawah 60 BPM dan diatas 100 BPM, dan ada penekanan pada tombol panic button, waktu yang dibutuhkan untuk pengiriman sms berdurasi sekitar 7 sampai 8 detik. Pada penelitian berikutnya akan dikembangkan sistim monitoring yang terintegrasi dengan aplikasi sosial media seperti What apps dan Telegram Messanger.

\section{Daftar Rujukan}

[1] Ananda Mohon Ghosh; Debashish Halder; S K Alamgir Hossain.2016. Remote health monitoring system through IoT, 5th International Conference on Informatics, Electronics and Vision (ICIEV).

[2]. Sarfraz Fayaz Khan, Health care monitoring system in Internet of Things (IoT) by using RFID, 2017 6th International Conference on Industrial Technology and Management (ICITM)

[3] S. Siva1, P. Suresh, S. Seeba Merlin and R. Punidha; A Smart heart rate sensing system in the internet of Internet of Things, IJCTA, 9(9), 2016, pp. 3659-3663

[4] Freddy Jimenez, Romina Torres; Building an IoT - aware healthcare monitoring system, 2015 34th International Conference of the Chilean Computer Science Society (SCCC)
[5]. Cloud standar Customer Council. Impact of Cloud Computing on Healthcare

Anggara Nasution, Roni.P, Rusfandi. 2018. Pembuatan Alat Monitoring Suhu Dan Daya Listrik Yang Dapat Di Baca Secara Online Pada Anechoic Chamber Di Laboratorium Antena Politeknik Negeri Padang. Jurnal temapela Vol.1 No.1 2018, hal: 1-6

Era Madona, Muhammad Irmansyah, Anggara Nasution. Sistem Informasi Untuk Posisi Dan Lama Duduk Dengan Smartphone Android Berbasis Mikrokontroler. Elektron Jurnal Ilmiah Vol 10 No.2 2018,hal: 1-5.

[8] M.irmansyah, Era Madona, Anggara.N, Roni.P. Low Cost Heart Rate Portable Device for Risk Patients with IoT and Warning System. Conference: 2018 International Conference on Applied Information Technology and Innovation (ICAITI). Indonesia

[9]. fk.ugm.ac.id/.../2017-03-04-lainnya-Kardiovaskuler-PenyebabUtama-Kematian-di-Indonesia

[10] Yoga Yuniadi, "Mengatasi Aritmia, Mencegah Kematian Mendadak". eJKI Vol. 5, No. 3, Desember 2017

[11] David L Larkai, Ruiheng Wu. Wireless Heart Rate Monitor in Personal Emergency Response System . 2015 IEEE 18th International Symposium on Design and Diagnostics of Electronic Circuits \& Systems

[12] Muhammad Farouq Bin Mustapha, Toni Anwar. Mobile Heart Rate Monitor for Myocardial Infarction Patients. 2017 IEEE 6th ICT International Student Project Conference (ICT-ISPC).

[13] G.Vijay Kumar, A.Bharadwaja, N.Nikhil Sai. Temperature and Heart Beat Monitoring System Using IOT. International Conference on Trends in Electronics and Informatics ICEI 2017 .

[14] Zainudin, N. Ahmad Mansor, W. Lee, Khuan Y. Sani, N. H Mohd Mahrim, S. A. Respiratory rate of photoplethysmogram signal from anaesthetic patients. ISCAIE 2015 - 2015 IEEE Symposium on Computer Applications and Industrial Electronics 